\title{
RELAPAROTOMY AFTER CESAREAN DELIVERY: A PROSPECTIVE STUDY
}

\author{
AKTHER R ${ }^{1}$, HOSSAIN T ${ }^{2}$, RASHID $\mathrm{M}^{3}$
}

\begin{abstract}
:
The present study aimed at exploring the causes of re laparotomy following Caesarean section and to find out the pathway how to avoid these complications. This is a hospital based prospective study conducted in the Department of Obstetrics and Gynaecology, Dhaka Medical College Hospital (DMCH), Dhaka, Bangladesh from August 2007 to August 2008. Bangladeshi pregnant women are at risk of serious complications during pregnancy and labor due to lack of antenatal, intra natal and postnatal care. DMCH is the largest referral hospital in Bangladesh and more than ten thousand patients admitted here each year with different pregnancy and child birth related complications. Among them, 54 puerpera needed re laparotomy after Caesarean section within 6 weeks of Caesarean Section. Of the 54 cases, 28 had primary $P P H, 14$ patients had secondary post-partum hemorrhage (PPH), 4 cases had puerperal sepsis and 3 women had wound dehiscence, and 5 cases had sub rectus hematoma. Irreversible hemorrhagic shock (12cases), cardio genic shock (1 case), not reversed from anesthesia (1 case), acute renal failure (3cases) and puerperal sepsis (1 case) were causes maternal death. It gave the overall case fatality rate was 33.33\%. Obstetric patients who return to the operation theater face potential death. This study will help us to identify the risk situations where re laparotomy may be needed and due precautions and prevention may be taken as far as possible to avoid this complications following caesarean section and thereby reduce maternal mortality and morbidity.
\end{abstract}

Key word: Cesarean section, laparotomy, maternal morbidity, maternal mortality, case fatality.

J Dhaka Med Coll. 2011; 20(1) : 57-62.

\section{Introduction:}

Cesarean Section (CS) is a life-saving technique for both mother and infant; however, it is a major abdominal operation that causes medical risks to a mother's health, including infections $(40-80 \%)^{1}$, hemorrhage (most often underestimated), and injury to other organs. During the last 20 years, cesarean section rates have risen to nearly $25 \%$ in some countries $^{2}$. In Bangladesh cesarean section rate is $8 \%$.For $5 \%$ of birth, the mother experienced excessive bleeding and 3\% (each) of births involved retained placenta and high fever with foul smelling discharge ${ }^{1}$. Maternal mortality two to four times greater after cesarean section than vaginal birth ${ }^{2}$. Cesarean section (CS) is easily the most common identifiable risk factor for development of puerperal complications. Most of the women are treated conservatively and few women needed relaparotomy. Prolonged rupture of the membrane ( $>24$ hours), chorioamnionitis, excessive number of digital vaginal examination, prolonged labour ( $>12$ hours), preeclampsia, intra partum and postpartum anemia, poor nutrition, low socioeconomic condition are the risk factors for development of complications. Risk of complications increases among women who attempted vaginal birth but ultimately was delivered by emergency cesarean section. Indication of CS, morbidity and mortality following CS in Bangladesh is not known. To address the complications following cesarean delivery, we critically evaluated cases of re laparotomy following cesarean delivery. The aim of this

1. Dr. Rabeya Akther, Assistant Chief Medical Officer, Bangladesh Bank Medical Center, Motijheel, Dhaka.

2. Dr. Toufiqua Hossain, Assistant Professor, Department of Obstetrics and Gynaecology, Dhaka Medical College, Dhaka.

3. Prof. Maliha Rashid, Ex-Professor, Department of Obstetrics and Gynaecology, Dhaka Medical College, Dhaka. Correspondence: Dr. Rabeya Akther, Assistant Chief Medical Officer, Bangladesh Bank Medical Center, Motijheel, Dhaka. Cell Phone: +8801817517100, Email: dr.r.akther@gmail.com 
study to identify the risk situations where re laparotomy may needed, the operative findings, the measure taken to save patient's life and the precautions that may be taken to prevent these emergency situation and maternal deaths.

\section{Methods:}

This was a cross-sectional study conducted in the Obstetrics and Gynaecology Department of Dhaka Medical College Hospital over a period of 13 months from August 2007 to August 2008. Fifty four women who underwent CS (Cesarean section) first and needed re laparotomy within 6 weeks of Cesarean section were included in this study. Cause of hospitalization, indication of cesarean section and re laparotomy, time interval between CS and re laparotomy ,operative findings, procedures undertaken during re laparotomy and causes of death were analyzed. All relaparotomy cases were performed under general anesthesia by senior obstetricians (e.g. registrar, resident surgeon, consultant and professor).

Cases having primary PPH was managed by giving rapid infusion of volume expander, hartman solution, oxytocics drugs (Injection Oxytocin 20 unit in one liter Hartman solution, injection methergin 2 ampule I.V. stat and 8 hourly, misoprostol $800 \mathrm{mg}$ per rectally) and 2 tablets 6 hourly and intrauterine balloon with condom to control uterine bleeding. Fresh blood and fresh frozen plasma were transfused to replace lost blood. When conservative management failed to stop PPH, patient's condition did not improved and investigation were remarkable, decision for surgical interventions were undertaken. Ligation of uterine artery, utero-ovarian vessels, B-Lynch brace suture and subtotal/total hysterectomy were done. In all cases more than one procedure were tried to control hemorrhage.

Patients who were readmitted/ referred with secondary hemorrhage, was treated with oxytocics drugs, antibiotics (ceftriaxone, metronidazole) and fresh blood and fresh frozen plasma transfusion. Complete blood count, coagulation profile, USG of lower abdomen, HVS for culture and sensitivity, estimation of â-HCG were done to find out the causes of uterine bleeding. Evacuation and curettage also done in specific cases and specimen sent for histopathological examination. When conservative management failed to stop PPH, patient's condition did not improved and investigation were remarkable, decision for surgical interventions were undertaken. In cases of wound dehiscence and rectus sheath hematoma, peritoneal cavity was opened and inspected routinely to exclude intra-peritoneal bleeding. In case of anuria, peritoneal cavity was opened to exclude ureteric injury .In cases of puerperal sepsis hysterectomy (3cases) was done to remove source of infection.

A questionnaire was designed encompassing all relevant clinical information which included data from admission register, OT register, report register, patient herself, patient's attendant and patient's file. Collected data checked and cleaned. Editing was done properly. Finally data was entered into the computer for statistical analysis by using MS EXCEL. Ethical clearance for the study was taken by the Departmental Ethical Committee.

\section{Results:}

During the study period a total of 15283 patients were admitted at labor emergency. Nearly six hundred or more women admitted with the complaint of postpartum hemorrhage and puerperal infection .Majority of them delivered by cesarean section (CS). Total 54 cases underwent laparotomy after CS, thirty eight CS done in the peripheral hospital and sixteen cases done in this hospital by junior doctors. In primary hemorrhage, laparotomy was done 15.6 hours after CS and in secondary hemorrhage, 17 days after CS.

Table-I shows indications for re laparotomy following CS. Of the 54 cases, twenty eight had primary hemorrhage. Atonic uterus (14 cases), loose knot at the corner of the uterine wound (1case), incomplete rupture of the uterus (1), failure to suture lower uterine segment with upper uterine segment ( 1 case), undiagnosed uterine wound (1), cervical tear (1), massive hemorrhage progress to shock ( 3 cases) and retained bits of placental tissue in placenta previa ( 6 cases) were the cause of primary hemorrhage . 
Fourteen patients had secondary hemorrhage, 4 cases had puerperal sepsis , 3 women had wound dehiscence, 5 cases had sub rectus hematoma, One case had bladder injury with acute pain abdomen, But no one had ureteric injury.

Table-II shows indication of cesarean section (CS). Indication of CS were include post cesarean section (7 cases), obstructed labor (7 cases), prolonged labor with foetal distress (4 cases), eclampsia (3 cases), heart disease (2 cases ), APH due to placenta previa (4 cases), Post CS placenta previa (5 cases) and repeat CS (2 cases). In remaining cases indications of CS were unknown. There was one case of post CS placenta previa accreta and caesarean hysterectomy was done due to uncontrolled PPH.

The procedures performed during laparotomy are shown in Table-III. Hysterectomy or subtotal hysterectomy was performed in 35 (64.81\%) cases and conservative surgery was done in 19 (35.19\%) cases. Among the conservative surgery, re suturing of uterine wound and repair of cervical tear 6 cases $(11.11 \%)$, ligation of uterine artery and ovarian vessels 3 cases (5.55\%), exploration and removal of sub-rectus hematoma, ligation of vessels in $5(9.25 \%)$ cases, repair of anterior abdominal wall 3 $(5.55 \%)$ cases and tightening of ligature 2 $(3.7 \%)$ cases. Table-IV shows the causes of maternal death after laparotomy. A total of eighteen mothers died 17.9 hours after laparotomy. Death occurs due to failure of adequate replacement therapy and irreversible hemorrhagic shock (12 cases), cardiogenic shock (1 case), not reversed from anesthesia (1 case), acute renal failure (3cases) and puerperal sepsis (1 case).

Table-I

Indications of laparotomy

\begin{tabular}{|c|c|c|}
\hline Variables & Causes & $\begin{array}{l}\text { No. of cases } \\
(\mathrm{n}=54)\end{array}$ \\
\hline Primary $\mathrm{PPH}$ & Atonic uterus & 14 \\
\hline \multirow[t]{5}{*}{ Shock and anuria } & Fail to suture lower uterine segment, internal hemorrhage & 4 \\
\hline & $\begin{array}{l}\text { Retain bits of placental tissue(placenta previa, post CS placenta } \\
\text { previa accrete, percreta) }\end{array}$ & 6 \\
\hline & $\begin{array}{l}\text { Loose knot at uterine corner,uterine injury, incomplete } \\
\text { uterine rupture, }\end{array}$ & 3 \\
\hline & Cervical tear & 1 \\
\hline & Total & 28 \\
\hline Secondary PPH & Infection & 14 \\
\hline Puerperal sepsis & Purulent discharge, uterus was infected, congested and necrotic & 4 \\
\hline Wound dehiscence, & Nothing abnormality detected in the peritoneal cavity & \\
\hline Burst abdomen & & 3 \\
\hline \multirow[t]{2}{*}{$\begin{array}{l}\text { Sub rectus } \\
\text { hematoma }\end{array}$} & $\begin{array}{l}\text { Torned vessels of rectus muscle, clotted blood under the } \\
\text { rectus sheath }\end{array}$ & 5 \\
\hline & Total & 26 \\
\hline Total & & 54 \\
\hline
\end{tabular}

Table-II

Indications of CS among the women who underwent laparotomy

\begin{tabular}{lc}
\hline Indication for CS delivery & Frequency $(n=54)$ \\
\hline (a) Post-cesarean pregnancy (History of CS once before) & 7 \\
(b) Obstructed labor & 7 \\
(c) Post-CS placenta previa & 5 \\
(d) Prolonged labor with fetal distress & 4 \\
(e) Placenta previa & 4 \\
(f) Hypertensive disorders & 3 \\
(f) Repeat cesarean pregnancy (History of CS twice before) & 2 \\
(h) Heart disease & 2 \\
(i) Unknown & 20 \\
\hline
\end{tabular}


Table-III

Procedures undertaken during laparotomy

\begin{tabular}{lc}
\hline Procedures & Frequency(n=54) \\
\hline Hysterectomy & $35(64.81 \%)$ \\
Conservative surgery & $19(35.19 \%)$ \\
Resuturing uterine wound \& repair of cervical tear & $6(11.11 \%)$ \\
Ligation of uterine artery and ovarian vessels & $3(5.55 \%)$ \\
Exploration and removal of sub rectus hematoma, ligation of vessels & $5(9.25 \%)$ \\
Repair of anterior abdominal wall & $3(5.55 \%)$ \\
Tightening of ligature & $2(3.7 \%)$ \\
\hline Total & $54(100 \%)$ \\
\hline
\end{tabular}

Table-IV

Maternal mortality after relaparotomy

\begin{tabular}{|c|c|c|c|c|}
\hline $\begin{array}{ll}\text { Cause of death } \\
\mathrm{de}\end{array}$ & $\begin{array}{l}\text { No. of } \\
\text { death }(n=18)\end{array}$ & Indication of laparotomy & Indication of CS & $\begin{array}{l}\text { Time interval } \\
\text { from CS to } \\
\text { laparotomy }\end{array}$ \\
\hline $\begin{array}{l}\text { Not Reversed } \\
\text { from anaesthesia }\end{array}$ & 1 & $\begin{array}{l}\text { intraperitoneal bleeding } \\
\text { following CS hysterectomy }\end{array}$ & Post CS placenta accreta & 27 hours \\
\hline Hemorrhagic Shock & 11 & Primary PPH & $\begin{array}{l}\text { EclampsiaPlacenta previa } \\
\text { (5 cases)Obstructed labor } \\
\text { Fetal distress (4cases) }\end{array}$ & 1 to 7 days \\
\hline Renal failure & 3 & Anuria with shock & $\begin{array}{l}\text { Post CS ( } 2 \text { cases }) \\
\text { Foetal distress }\end{array}$ & 40 hours \\
\hline Hemorrhagic Shock & 1 & Secondary PPH & & 7 days \\
\hline Puerperal sepsis & 1 & Puerperal peritonitis & prolonged labor & 3 weeks \\
\hline Cardiac arrest & 1 & Primary PPH following CS & Placenta previa & 7 hours \\
\hline
\end{tabular}

\section{Discussion:}

In Bangladesh, 85\% delivery taken place at home and only $15 \%$ in the health facility. Incidence of caesarean section in Bangladesh is $8 \% .^{2} \mathrm{PPH}$ and puerperal sepsis causes $4.7 \%$ and $6.25 \%$ hospital admission in 2007 and 2008 in $\mathrm{DMCH} .{ }^{3}$ There are very few large case series in the world literature regarding repeat laparotomy following cesarean delivery. One such series from a teaching hospital in Ghana, with a CS rate of $17 \%$, showed a relaparotomy rate of $0.7 \%$ out of a total of 36100 deliveries. ${ }^{6}$ In that study, the commonest indication of CS were cephalo-pelvic disproportion and obstructed labor, and the commonest indication of re laparotomy was atonic uterus. In another series from a teaching hospital in India, the incidence of CS was 34.8\% where re laparotomy was needed in $0.33 \%$ of CS and the incidence of laparotomy following vaginal delivery was $0.14 \% .^{8}$

One of the limitations of the study was that 38 of the 54 cases, CS were done at peripheral hospitals. It is therefore not possible to calculate the exact overall incidence since we do not know the denominator. In this study, the incidence of CS was $34.86 \%$ in $\mathrm{DMCH}$ and repeat laparotomy was needed in $0.315 \%$ of cases. This finding is compatible with the Indian study. ${ }^{8}$ During the same period, there was no cases of laparotomy following vaginal delivery in hospital delivery cases. This finding is opposite to Indian study and indicating better management of vaginal delivery. ${ }^{8}$

Caesarean section was done in the second stage of labor as an emergency procedure. CS 
done in second stage with an impacted fetal head can be technically difficult and is associated with increased trauma to the lower uterine segment and adjacent structures (tear extension to involve the uterine arteries, cervix, vagina and bladder), increased hemorrhage and infection. ${ }^{7,8,9}$ Hemorrhage necessitated the patient's return to the operating theater following $0.2 \%$ cases of $\mathrm{CS}^{10}$. Ligation of vessels and B-lynch suture was not enough to control PPH. ${ }^{11}$ Vessel ligation was performed in $35 \%$ of cases before proceeding to hysterectomy in a series of peri partum hysterectomy. ${ }^{12,13}$ Secondary PPH following CS is often difficult to control by vessel ligation. The exact cause of PPH could not be detected, as ultra sound failed to demonstrate any retained bits of placental tissue. ${ }^{6}$ During re laparotomy, it was found that uterine wound was open, the lower uterine segment could not be identified, uterus was edematous, congested, infected and necrotic, adherent with the surround structures. In this study, hysterectomy were done in 2ndary hemorrhage (12 cases) with the purpose of to remove infective focus. ${ }^{14}$ Currently, there are no recommendations for treatment of secondary $\mathrm{PPH}^{7}$ following $\mathrm{CS}$ where no cause can be identified. Proper hemo stasis during the CS with prophylactic use of antibiotics ${ }^{1}$ may well reduce infection but aseptic precaution in all steps of labor from per vaginal examination to end of puerperium is the goal of infection prevention. ${ }^{14}$ Rectus sheath hematoma was another common indication of laparotomy ${ }^{7}$ $(10.52 \%)$. It was seen in cases who developed DIC (eclampsia, severe infection) and injury to vessels of rectus muscle. Proper haemostasis before suturing the rectus sheath can minimize the incidence of rectus sheath hematoma. Restlessness, tachycardia, hypotension and anuria following CS should raise suspicion of concealed hemorrhage. In this study there were nine cases of placenta previa. The morbidity and mortality related to placenta previa (increta and accrete) is still a nightmare of the obstetrician in this century $^{15}$. In cases of placenta previa, it is wise to refer the patient to higher centre in diagnosed cases and if undiagnosed, proper hemostasis should be done before closing abdominal wound. Where hemostasis is doubtful, one must examine the vagina and keep a drain before closing the peritoneal cavity to ensure the absence of active bleeding 7 . Prophylactic balloon catheter of uterine cavity may be practiced to reduce the risk of $\mathrm{PPH}^{16}$. $\mathrm{PPH}$ is the most common child birth related complication and surgical treatment is the most definitive treatment. Every obstetrician must be well trained to assess the emergency situation and also in surgical methods. PPH is not always preventable but can be definitely treatable. ${ }^{17}$

Post-operative management of these patients is very important because majority of the patient died within 17.9 hours of laparotomy. Maternal mortality was quite high in patients who required laparotomy following CS. It was $9.1 \%$ in the African series ${ }^{6}$ and $12.1 \%$ in Indian series $^{7}$ and $33.33 \%$ in this study. This finding is very high in comparison with the African and Indian study. Probably triple delay is responsible for this near miss mortality. In this study, because of limited ICU facility, only one case admitted in intensive care unit and ten cases $(18.51 \%)$ required massive blood transfusion.

Home delivery is almost universal in Bangladesh ${ }^{2}$. Critical indicators to comprehensively monitor skilled health attendance would include not just skilled birth attendants but also access to basic and comprehensive emergency obstetric care services and post-partum care. However to reduce maternal morbidity and mortality, more hospital delivery will mean a reduction in the overall rate of complication ${ }^{18}$, including relaparotomy.

\section{Conclusion:}

Cesarean delivery is a life-saving and most common obstetric operation. To make it safe every effort must be adopted. Relaparotomy may be considered a near miss maternal mortality situation. To improve the standard of service from antenatal care to till delivery is essential for better outcome.

\section{Acknowledgment:}

We are thankful to the patient of the study, their families, nurses and staff of operation 
theater, labour ward and post operative ward, anesthetists of Dhaka Medical College Hospital, for allowing me to carry out the study.

\section{References:}

1. Poggi SBH, Kapernick PS. eds. Post partum Hemorrhage and abnormal puerperium. In: Current obstetric Gynaecologic Diagnosis and treatment, $8^{\text {th }}$ ed. New York: Appleton \& Lange; 1994. p.543.

2 A Tool to Estimate the Risks of Repeat Cesarean Section. PLoS Med 2(9): e325 Published: September 13, 2005.

3 Bangladesh Demographic and household survey 2007 ,xxvii.

4 Review of availability and use of emergency obstetric care [EmOC] services in Bangladesh; conducted by Associates for Community \& Population Research (ACPR); October 2001; UNICEF.

5 Ahmed S, Islam A, Mitra DK, Khanum PA, BarkatE-Khuda. Use of a sub-district hospital for management of obstetric complications in rural Bangladesh [WP124, 1999] ICDDR,B publication.

6 Ahmed S, Khanum PA, Islam A. Maternal morbidity in rural Bangladesh: where do women go for care? [WP113, 1998] ICDDR, B publication.

7 Seffah JD. Relaparotomy after caesarean section. Int J Gynecol Obstet 2005; 88: 253-7.

8 Seal SL, Kamilya G, Bhattacharyya SK, Mukherji J, Bhattacharyya AR. Relaparotomy after cesarean delivery: Experience from an Indian teaching hospital. J Obstet Gynaecol Res 33; 6: 804-9.

9 Allen VM, O'Connell CH, Baskett TF. Maternal and perinatal morbidity of caesarean delivery at full cervical dilatation compared with caesarean delivery in the first stage of labour. $\mathrm{Br} \mathrm{J}$ Obstet Gynaecol 2005; 112: 986-90.

10 Fasubaa DB, Ezechi OC, Orji EO et al. Delivery of the impacted head of the fetus at caesarean section after prolonged obstructed labour: a randomized comparative study of two methods. Obstet Gynecol 2002; 22: 375-8.

11 Ashton P, Beischer N, Cullen J, Ratten G. Return to theatre - experience at the Mercy Maternity Hospital, Melbourne 1971-1982. Aust NZ J Obstet Gynaecol 1985; 25: 159-69.

12 Cunningham FG, Leveno KJ, Bloom SL, Hauth JC, Gilstrap LC III, Wenstrom KD. Williams Obstetrics. 22 $2^{\text {nd }}$ ed. New York: McGraw-Hill; 2005. p. 828-54.

13 Yamani Zamzami TY. Indication of emergency peripartum hysterectomy: review of 17 cases. Arch Gynecol Obstet 2003; 268: 131-5.

14 Farhana D, Munira P, Begum MR, et al. Quality assurence of Emergency Obstetric care (EmOC) service at sub district level. AOCOG 2007 Golden Jubilee of Federation, The XXth Asian and Oceanic Congress of Obstetrics and Gynaecology, September 21-25, 2007. Tokyo, Japan. p.203.

15 Shih JC. Placenta Accreta in the 21st Century The Additional Horizon with novel hemostasis Technique: AOCOG 2007 Golden Jubilee of Federation, The XXth Asian and Oceanic Congress of Obstetrics and Gynaecology, September 21-25, 2007. Tokyo, Japan. p.161-2.

16 Siddiqui M, Rashid M. Balloon Temponade to pervent primary PPH in jaundice - A Prospective Study. J Bangladesh Coll Phys Surg 2008; 26(1): 22-5.

17 Doshi HU. Post Partum Hemorrhage - Medical and Surgical management: AOCOG 2007 Golden Jubilee of Federation, The XXth Asian and Oceanic Congress of Obstetrics and Gynaecology, September 21-25, 2007 Tokyo, Japan. p.150.

18 Geller SE, Goudar SS, Adams MG, Naik VK, Patel A, Bellad MB, et al. Factors associated with Acute post partum hemorrhage in low risk women delivering in rural India. Int $\mathrm{J}$ Obstet Gynecol 2008; 101: 94-9. 